doi:10.4149/neo_2017_606

\title{
Long noncoding RNA ASAP1-IT1 promotes cancer stemness and predicts a poor prognosis in patients with bladder cancer
}

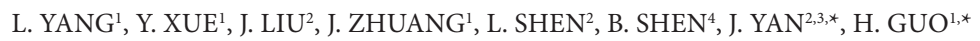 \\ ${ }^{1}$ Department of Urology, Drum Tower Hospital, Medical School of Nanjing University, Institute of Urology, Nanjing University, 321 Zhongshan \\ Rd., Nanjing 210008, Jiangsu, People's Republic of China; ${ }^{2}$ State Key Laboratory of Pharmaceutical Biotechnology and MOE Key Laboratory of \\ Model Animals for Disease Study, Model Animal Research Center, Nanjing University, Nanjing, Jiangsu 210061, China; ${ }^{3}$ Collaborative Innova- \\ tion Center for Genetics and Development, 2005 SongHu Road, Yangpu District, Shanghai 200438, China; ${ }^{4}$ epartment of Urology, Shanghai \\ General Hospital, Shanghai Jiaotong University, Shanghai, 200080, China
}

*Correspondence: dr.guohongqian@gmail.com, yanjun@nju.edu.cn

Received January 9, 2017 / Accepted March 22, 2017

\begin{abstract}
Urinary bladder cancer (UBC) is one of the most common urogenital malignancies. Cancer stem-like cells (CSCs) play a vital role in tumor development and recurrence. Long noncoding RNAs (lncRNAs) are reported to influence cancer progression via transcriptional, posttranscriptional or epigenetic regulation. Dysregulation of several lncRNAs has been implicated in UBC. In our study, we found that an uncharacterized lncRNA, ASAP1-IT1, was overexpressed in UBC tissues compared with adjacent non-malignant tissues. High ASAP1-IT1 expression levels in UBC specimens were correlated with advanced tumor stage, higher clinical stage, poor pathological differentiation and bad overall survival. We further found that depletion of ASAP1-IT1 in T24 cells by RNA interference reduced the stemness of bladder cancer, whereas forced overexpression of ASAP1-IT1 in J82 cells enhanced cancer cell stemness by sphere assay, ALDEFLUOR and flow cytometry assay on CD44 ${ }^{+}$ population. Our data suggest that ASAP1-IT1 plays an oncogenic role in bladder cancer and can be used as a potential prognostic and therapeutic target.
\end{abstract}

Key words: bladder cancer, long noncoding RNA, ASAP1-IT1, cancer stem-like cells

Urinary bladder cancer is one of the most common urogenital malignancies, with estimated 76,690 new cases and 16,390 deaths in USA during 2016 [1]. More than $90 \%$ of bladder cancers are urothelial cancer. Among them, 70-80\% of bladder cancers are non-muscle invasive tumor (NMIBC), with frequent mutations of FGFR3 and H-RAS. 20-30\% of bladder cancers are muscle invasive tumor (MIBC), with high mutations of $\mathrm{p} 53$ and $\mathrm{Rb}$. The latter group has very poor prognosis, with five-year survival $<50 \%$ and common progression to metastasis. The medium survival is $12-15$ months for metastatic patients. Importantly, $10-15 \%$ of NMIBC patients will eventually progress to invasion $[2,3]$. Although great improvements in diagnosis and therapy for UBC have been made, the direct cost of UBC per patient ranks first among all cancers $[4,5]$.

In recent years, cancer stem-like cells (CSCs) have been found in a variety of human malignancies, including breast and lung cancer [6]. CSCs, which have the principal properties of self-renewal, clonal tumor initiation capacity and clonal long-term repopulation potential, only account for a small proportion of all tumor cells within heterogenous tumor mass [7]. However, CSC population plays a vital role in tumor initiation, progression, metastasis, chemoresistance, and recurrence. Many specific markers are used to identify, characterize and isolate CSCs. The phenotypic and functional properties of CSCs from UBC tissues have been well studied $[8,9]$. Several proteins, such as CD44, ALDH1A1, and CK5/14 are characterized as CSC markers of UBC. High expression levels of these markers in tumor tissues are correlated with poor prognosis of UBC patients [10,11].

LncRNAs are generally defined as RNA transcripts longer than 200 nucleotides with no protein-coding potential. Recent reports suggest that lncRNAs play an important part in human cancers, which influence all the "hallmarks of cancer" [12, 13]. The regulatory role of lncRNAs in normal stem cells has been well investigated [14]. As CSCs share some properties 
with normal stem cells, lncRNAs may also influence the state of CSCs [15]. Some oncogenic lncRNAs, such as MALAT-1, DANCR and HOXA11-AS, have been reported to enhance stem-cell like properties and promote cancer progression in pancreatic cancer, hepatocellular carcinoma and cervical cancer cells, respectively [16-18].

Human chromosome $8 \mathrm{q} 24$ is frequently amplified in UBCs [19]. Though on this chromosome region several oncogenes, such as c-Myc and ASAP1, have been associated with tumor metastasis and poor cancer survival [20,21], only a few lncRNAs, such as PVT1 and PRNCR1, in this region have been implicated in cancers $[22,23]$. So far we know little about the alteration of lncRNAs at $8 \mathrm{q} 24$ in UBC patients. LncRNA ASAP1-IT1, with full length of $1,179 \mathrm{bp}$, is an intronic transcript of the ASAP1 gene. Few reports have demonstrated its role in cancer development to date.

In the present study, we identified the overexpression of ASAP1-IT1 in human UBC samples and cell lines, and its overexpression was correlated with advanced tumor stage and high clinical stage. In essence, high expression level of ASAP1-IT1 predicted poor clinical outcome in UBC patients. By knockdown and overexpression of ASAP1-IT1 in human UBC cells, we proved that ASAP1-IT1 plays a pivotal role in regulation of UBC stemness. Thus, ASAP1-IT1 may be a potential prognostic biomarker for UBC diagnosis and therapy.

\section{Patients and methods}

Patients and specimen collection. Fifty-eight UBC patients who received radical cystectomy at Drum Tower Hospital affiliated to Nanjing University were included in the study. The patients had not been treated with chemotherapy or radiation therapy before surgery. Clinicopathological data such as age, gender, histological differentiation, lymph nodal status, and pathological stage were obtained at the same time. UBC specimens and adjacent normal tissues, which were at least $3 \mathrm{~cm}$ far away from cancer lesions were obtained and immediately frozen in liquid nitrogen and stored at $-80^{\circ} \mathrm{C}$ until later use. The protocols were approved by the Ethics Committee of Drum Tower Hospital for tissue sample collection and informed consent was obtained from all subjects.

Cell culture. Human UBC cell lines (T24, J82, UMUC3, RT4 and 5637) were purchased from the Cell Bank of Type Culture Collection, Chinese Academy of Science (Shanghai, China). Cell lines were maintained in RPMI 1640 medium (Life Technologies), supplemented with 10\% FBS (Hyclone Laboratories, South Logan, UT, USA) and 100 units $/ \mathrm{ml}$ penicillin and $100 \mu \mathrm{g} / \mathrm{ml}$ streptomycin at $37^{\circ} \mathrm{C}$ with $5 \% \mathrm{CO}_{2}$.

Sphere formation assay. About $1.0 \times 10^{4} \mathrm{UBC}$ cells per well were trypsinized, washed and seeded in the 6-well ultra-low attachment plates (Corning, Steuben County, NY, USA) in DMEM/F12, supplemented with $10 \mathrm{ng} / \mathrm{ml}$ EGF (PeproTech, AF-100-15, Rocky Hill, NJ, USA) and $10 \mathrm{ng} / \mathrm{ml}$ human recombinant bFGF (PeproTech, 100-18B, Rocky Hill, NJ, USA).
After culturing for 5-7 days, spheres were photographed and counted for sphere with diameter $\geq 50 \mu \mathrm{m}$.

Flow cytometry. T24 and J82 cells with high ALDH enzyme activity were identified by ALDEFLUOR kit (Stem Cell Technologies, Vancouver, Canada). $5 \mu$ l of activated ALDEFLUOR reagent was added to $1 \mathrm{ml}$ single cell suspension and mixed well. An ALDH-specific inhibitor, Diethylaminobenzaldehyde (DEAB), was added to $500 \mu$ of the cell suspension prior to staining as a negative control. The two parts were incubated at $37^{\circ} \mathrm{C}$ for $40 \mathrm{~min}$. CD44 (BD Biosciences, San Jose, CA, USA, 1:25 dilution) was added to cells suspended in PBS/0.5\% BSA and incubated for $15 \mathrm{~min}$ at $4{ }^{\circ} \mathrm{C}$. Then results were analyzed on a BD FACScan flow cytometer.

Small interfering RNA transfection. Small interfering RNA (siRNA) transfection was conducted using Lipofectamine 3000 Reagent (Invitrogen, Carlsbad, CA, USA), according to the manufacturer's instructions. siRNAs were synthesized by Shanghai Genepharma Co.,Ltd and their sequences were shown as follows: ASAP1-IT1 siRNA-1 (si 1\#): 5'-CAGCUACAUUGUGUGCUUAtt-3'; ASAP1-IT1 siRNA-2 (si 2\#): 5'-GCCUCCCUAGGUCU CUGUUUCUUCUtt-3'; scramble control siRNA (si NC): 5'-UUCUCCGAACGUGUCACGUtt-3'.

Plasmid construction and transfection. For ASAP1-IT1 overexpression, we cloned ASAP1-IT1 full length into lentiviral expression vector pCDH. For cell transfection, $1 \mu \mathrm{g}$ plasmid (pCDH-ASAP1-IT1) or empty vector, were transfected into cells using Lipofectamine 3000 Reagent (Invitrogen, Carlsbad, CA, USA), according to the manufacturer's instructions.

RNA isolation and quantitative reverse transcriptionquantitative PCR. Total RNA of cultured cells or tissues was isolated using TRIzol reagent (Invitrogen). RNA was reverse transcribed into cDNA by Prime-Script RT-PCR kit (TaKaRa, Dalian, China) as manufacturer's instructions. The expression levels of genes were measured by qRT-PCR using SYBR Green in an ABI 7500 StepOne Plus Real Time PCR instrument (Applied Biosystem, USA). The primer sequences used for qRT-PCR were as follows: for ASAP1-IT1, 5' -AAACATCATCCCCAGAGTGG-3' (forward), 5'- GCCTTGCTCACCTCTGAAAC-3' (reverse); for ALDH1A1, 5'-CTGTGTTCCAGGAGCCGAAT -3'(forward), 5'-TGCCTTGTCAACATCCTCC TTA-3' (reverse); for CD44, 5' - CTGCCGCTTTGCAGGTGTA-3' (forward), 5'-CATTGTGGGCAAGGTGCTATT-3' (reverse); for $\beta$-Actin, 5'-TCTGGCTGAGGCTGGTTGAC-3' (forward), 5'-CTCCTTAATGTCACGCACGAT-3' (reverse). The relative expression levels of genes were calculated by using the $2^{-\Delta \Delta \mathrm{Ct}}$ method in which higher $2^{-\Delta \Delta \mathrm{Ct}}$ reflected higher expression.

Protein extraction and Western blot analysis. Cells were lyzed in RIPA buffer. $20 \mu \mathrm{g}$ proteins in the lysates were separated by SDS-PAGE and transferred onto PVDF membrane (Millipore, Billerica, MA, USA). After blocking with 5\% non-fat milk in PBST, the primary antibodies for ALDH1A1 (Proteintech Group, 22109-1-AP, Chicago, IL, USA), CD44 
(Cell Signaling Technology, \#3570, Beverly, MA, USA) and $\beta$-Actin (Bioworld Technology) were used. The membranes were then washed with PBST three times and incubated with horseradish peroxidase (HRP)-conjugated secondary antibody. The Western blots were visualized using the enhanced chemiluminescence reagents (Millipore, WBKLS0100).

Statistical analysis. Data were analyzed by SPSS 19.0 software (SPSS, Chicago, IL, USA). Each experiment was repeated three times. The difference of ASAP1-IT1 expression level between cancer tissues and corresponding normal tissues was analyzed by paired $t$ test. Student's $t$ test was used to analyze other differences between two groups. The $\chi^{2}$ test was used to compare the associations between ASAP1-IT1 expression and clinicopathologic variables of the UBC samples. The postoperative survival curves were calculated using the Kaplan-Meier method and differences in the survival rates were analyzed using the log-rank test. Data were presented as mean \pm standard deviation. The statistical significance was defined as a $p<0.05$. All graphs were plotted using GraphPad Prism 5.0 (GraphPad Software, La Jolla, CA, USA).

\section{Results}

ASAP1-IT1 was upregulated in UBC tissues and cell lines. ASAP1-IT1 expression level in 58 pairs of UBC and adjacent normal tissues was tested by quantitative real-time PCR. ASAP1-IT1 was overexpressed in most UBC tissues, compared to corresponding normal tissues $(\mathrm{p}<0.01$; Figure $1 \mathrm{~A})$. We further tested ASAP1-IT1 expression level in 5 UBC cell lines. High expression of ASAP1-IT1 was found in all of these cell lines compared to 4 normal urothelial tissues (Figure 1B).

High expression of ASAP1-IT1 in UBC was correlated with poor prognosis. Among the 58 pairs of UBC samples and adjacent normal tissues, the medium expression level of ASAP1-IT1 (cancer tissues compared to adjacent normal tissues) was 1.42 , which was used as the cut-off value to determine low or high ASAP1-IT1 expression. The correlation between ASAP1-IT1 expression level and UBC patients' clinicopathological parameters was analyzed. Higher ASAP1-IT1 expression levels were significantly associated with higher pathological TNM stage $(\mathrm{p}=0.017)$, more tumor invasion $(\mathrm{p}=0.014)$ and poor pathological differentiation $(\mathrm{p}=0.025)$. However, no significant differences existed with respect to age, gender, nerve invasion, vascular invasion, lymph node metastasis $(\mathrm{p}=0.16$; Table 1$)$.

Overall survival curve of patients who underwent radical cystectomy was shown in Figure 1C. Patients in high ASAP1IT1 expression group had significantly shorter survival time compared with those in low expression group $(\mathrm{p}=0.01)$. Medium overall survival times for ASAP1-IT1 high and low groups were 16 months and 36 months, respectively (Figure 1C). Univariate and multivariate analyses of patient overall survival were performed (Table 2). Both analyses revealed that ASAP1-IT1 was an independent prognostic indicator for overall survival of patients with UBC.
A

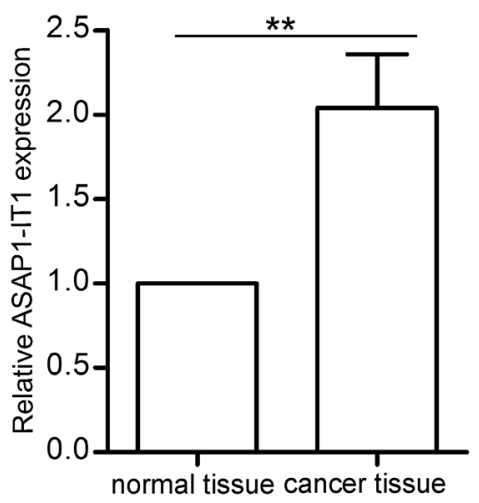

B

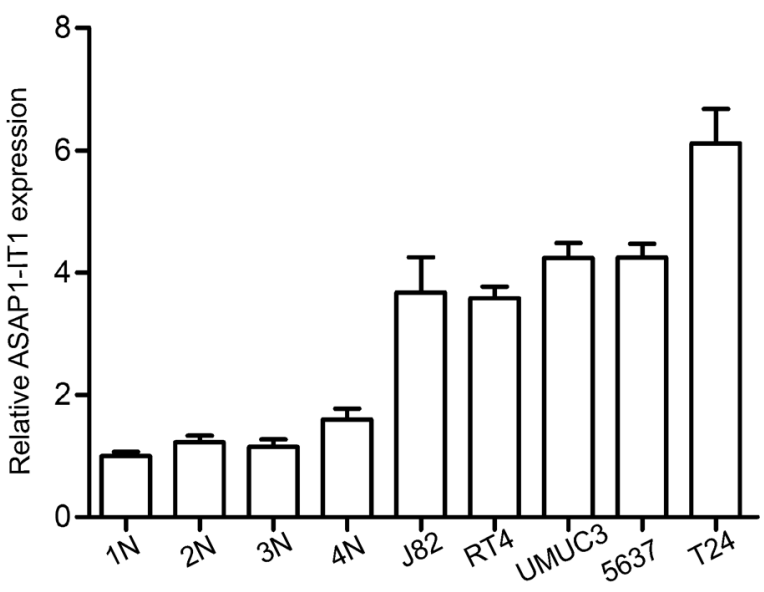

C

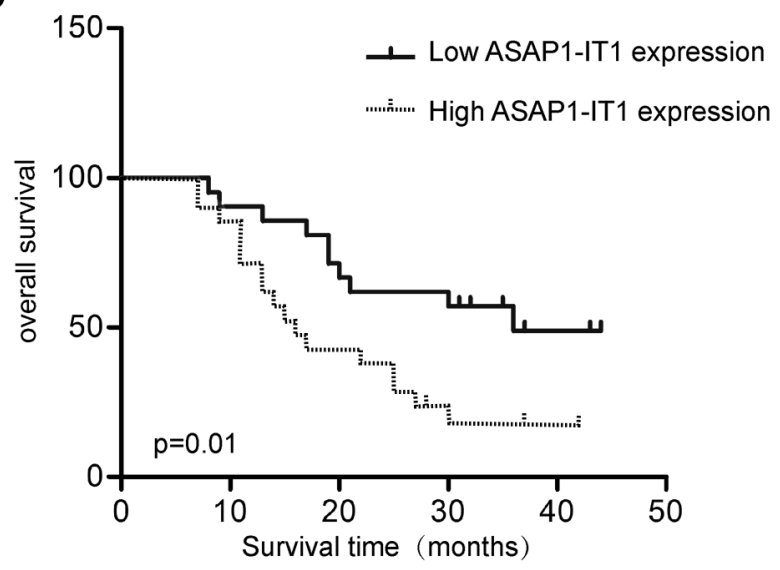

Figure 1. ASAP1-IT1 was upregulated in UBC tissues and cell lines and correlated with poor prognosis. A. ASAP1-IT1 levels in 58 human UBC samples and their adjacent normal tissues tested by qRT-PCR, $\beta$-Actin was used as control. $2^{-\Delta \Delta C \mathrm{Ct}}$ was used as the relative expression of ASAP1-IT1 in both groups. B. ASAP1-IT1 expression in 5 bladder cancer cell lines (J82, RT4, UMUC3, 5637 and T24) and 4 cases of normal tissues (1N to $4 \mathrm{~N}$ ). C. Kaplan-Meier overall survival curves of UBC patients with different expression levels of ASAP1-IT1, 42 cases who had the follow-up information were included. ${ }^{\star *} \mathrm{p}<0.01$. 
Table 1. Correlation between ASAP1-IT1 and clinicopathological parameters of UBC patients.

\begin{tabular}{|c|c|c|c|c|c|}
\hline \multirow{3}{*}{$\begin{array}{l}\text { Clinicopathological } \\
\text { parameters }\end{array}$} & \multicolumn{4}{|c|}{ ASAP1-IT1 expression } & \multirow{3}{*}{ p-Value } \\
\hline & \multicolumn{2}{|c|}{ Low $(n=29)$} & \multicolumn{2}{|c|}{$\operatorname{High}(n=29)$} & \\
\hline & $\mathrm{n}$ & $\%$ & $\mathrm{n}$ & $\%$ & \\
\hline Age & & & & & 0.790 \\
\hline$<65$ & 12 & 41.4 & 13 & 44.8 & \\
\hline$>=65$ & 17 & 58.6 & 16 & 55.2 & \\
\hline Gender & & & & & 1.000 \\
\hline Male & 25 & 86.2 & 26 & 89.7 & \\
\hline Female & 4 & 13.8 & 3 & 10.3 & \\
\hline Tumor number & & & & & 0.150 \\
\hline Single & 11 & 37.9 & 6 & 20.7 & \\
\hline Multiple & 18 & 62.1 & 23 & 79.3 & \\
\hline Tumor stage & & & & & $0.014^{*}$ \\
\hline $\mathrm{T} 1$ or $\mathrm{T} 2$ & 23 & 79.3 & 14 & 48.3 & \\
\hline $\mathrm{T} 3$ or $\mathrm{T} 4$ & 6 & 20.7 & 15 & 51.7 & \\
\hline Nerve invasion & & & & & 0.240 \\
\hline Absent & 23 & 79.3 & 19 & 55.6 & \\
\hline Present & 6 & 20.7 & 10 & 34.4 & \\
\hline Vascular invasion & & & & & 0.290 \\
\hline Absent & 19 & 55.6 & 15 & 51.7 & \\
\hline Present & 10 & 34.4 & 14 & 48.3 & \\
\hline Lymph node metastasis & & & & & 0.160 \\
\hline Absent & 26 & 89.7 & 22 & 75.9 & \\
\hline Present & 3 & 10.3 & 7 & 24.1 & \\
\hline Clinical stage (pTNM) & & & & & $0.017^{\star}$ \\
\hline I or II & 21 & 72.4 & 12 & 41.4 & \\
\hline III or IV & 8 & 27.6 & 17 & 58.6 & \\
\hline Differentiation & & & & & $0.025^{\star}$ \\
\hline Well or moderate & 8 & 27.6 & 1 & 3.4 & \\
\hline Poor & 21 & 72.4 & 28 & 96.6 & \\
\hline
\end{tabular}

The data were analyzed by $\chi^{2}$ test or Fisher's exact test, ${ }^{*} \mathrm{p}<0.05$.

Knockdown of ASAP1-IT1 inhibited UBC cell stemness. As cancer stemness is involved in cancer progression, recurrence, metastasis and chemoresistance, we further detected whether ASAP1-IT1 would influence the stemness of UBC. Results mentioned above indicated that ASAP1-IT1 was relatively overexpressed in T24 and relatively underexpressed in J82 among all 5 UBC cell lines examined (Figure 1B).

To further characterize the role of ASAP1-IT1 in UBC cells, we knocked down ASAP1-IT1 by 2 different siRNAs in T24 cells (Figure 2A). In these two groups, we found that depletion of ASAP1-IT1 significantly reduced the sphere number by sphere formation assay (Figure 2B). The sizes of spheres in two ASAP1-IT1 knockdown groups were also smaller than those in control group (Figure 2C). As $\mathrm{ALDH}^{\text {high }}$ or $\mathrm{CD} 44^{+}$cancer cell subpopulations were generally considered as CSC population in multiple cancers, we examined the CSCs population changes in UBC cells by flow cytometry, when ASAP1-IT1 was knocked down. Compared with control group, ASAP1-IT1 depletion significantly and remarkably reduced the ALDH ${ }^{\text {high }}$ population, from $11.4 \%$ to $5.1 \%$ and $5.4 \%$ (Figure 2D and Supplementary Figure 1A). The CD $44^{+}$subpopulation was also reduced from $21.7 \%$ to $1.93 \%$ and $1.96 \%$ (Figure $2 \mathrm{E}$ ). The expression levels of ALDH1A1 and CD44, two CSC markers for UBC, were both decreased at mRNA and protein levels in ASAP1-IT1 knockdown group (Figure 2F and 2G). Taken together, the results above showed that ASAP1-IT1 is required for UBC cell stemness.

Overexpression of ASAP1-IT1 enhanced stemness of bladder cancer. To further confirm the effects of ASAP1-IT1 on UBC cells, we re-introduced ASAP1-IT1 in J82 cells, which showed a relatively low expression level of ASAP1-IT1 (Figure 1B). The expression level of ASAP1-IT1 in experimental group is about 6 folds higher than control vector group by qRT-PCR assay (Figure 3A). ASAP1-IT1 overexpression in J82 cells increased sphere number and sphere size significantly (Figure 3B and 3C). More ALDH ${ }^{\text {high }}$ (Figure 3D and Supplementary Figure 1B) or $\mathrm{CD} 44^{+}$(Figure $3 \mathrm{E}$ ) subpopulation were detected in J82 cells with ASAP1-IT1 overexpression. Consistently, high ASAP1-IT1 level increased the expression levels of ALDH1A1 and CD44 in J82 cells (Figure 3F). Overall, our data support that ASAP1-IT1 is sufficient and necessary for the maintenance of UBC cell stemness.

Table 2. Univariate and multivariate analyses for overall survival (Cox proportional hazards regression model)

\begin{tabular}{|c|c|c|c|c|c|c|}
\hline \multirow[t]{2}{*}{ Risk factors } & \multicolumn{3}{|c|}{ Univariate analysis } & \multicolumn{3}{|c|}{ Multivariate analysis } \\
\hline & HR & $95 \% \mathrm{CI}$ & p-value & HR & $95 \% \mathrm{CI}$ & $\mathrm{p}$-value \\
\hline Age & 0.978 & $0.941-1.11$ & 0.263 & 0.981 & $0.934-1.03$ & 0.424 \\
\hline Gender & 0.982 & $0.294-3.27$ & 0.976 & 0.610 & $0.149-2.50$ & 0.492 \\
\hline Tumor number & 1.308 & $0.570-2.99$ & 0.526 & 1.36 & $0.434-4.24$ & 0.601 \\
\hline Tumor stage (pT) & 0.539 & $0.252-1.15$ & 0.111 & 1.10 & $0.364-3.30$ & 0.870 \\
\hline Nerve invasion & 0.505 & $0.228-1.12$ & 0.092 & 0.589 & $0.187-1.85$ & 0.365 \\
\hline Vascular invasion & 0.852 & $0.395-1.84$ & 0.684 & 1.04 & $0.329-3.26$ & 0.954 \\
\hline Lymph node metastasis & 0.797 & $0.187-3.39$ & 0.759 & 0.828 & $0.141-4.85$ & 0.834 \\
\hline Differentiation & 0.702 & $0.211-2.33$ & 0.563 & 0.915 & $0.223-3.75$ & 0.902 \\
\hline ASAP1-IT1 expression & 0.382 & $0.172-0.84$ & $0.017^{*}$ & 0.379 & $0.152-0.947$ & $0.038^{*}$ \\
\hline
\end{tabular}

HR hazard ratio, $95 \%$ CI $95 \%$ confidence interval, ${ }^{*} \mathrm{p}<0.05$. 


\section{Discussion}

In this study we identified an unknown lncRNA, ASAP1IT1, which is overexpressed in human UBC specimens. Its overexpression was positively correlated with UBC tumor stage, clinical stage and poor overall survival of patients. We also proved that ASAP1-IT1 is sufficient and necessary for maintenance of UBC cell stemness.

ASAP1-IT1 is located at human chromosome 8q24, which is one of the most commonly amplified regions in multiple cancers [19, 24-26]. In UBC patients, its amplification was detected in $9 \%$ of primary tumors $(n=131)$ and $33 \%$ of dis-
A

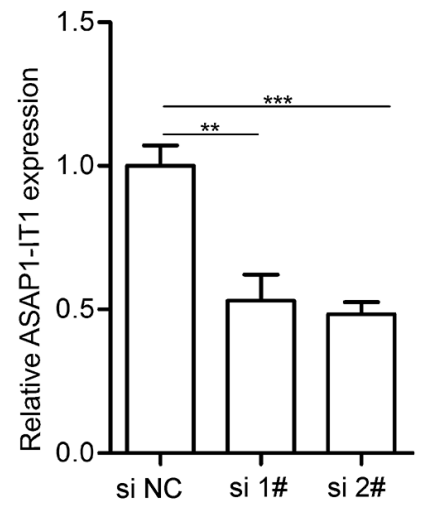

B

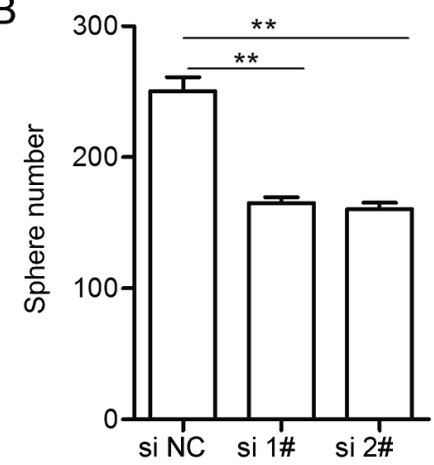

C
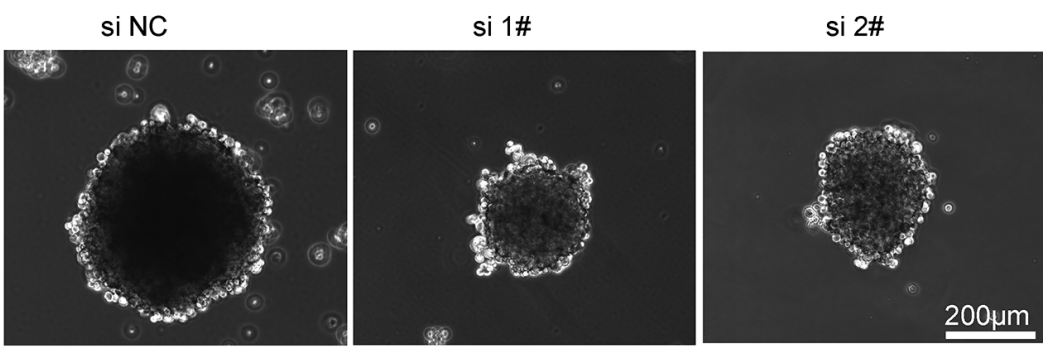

$E$

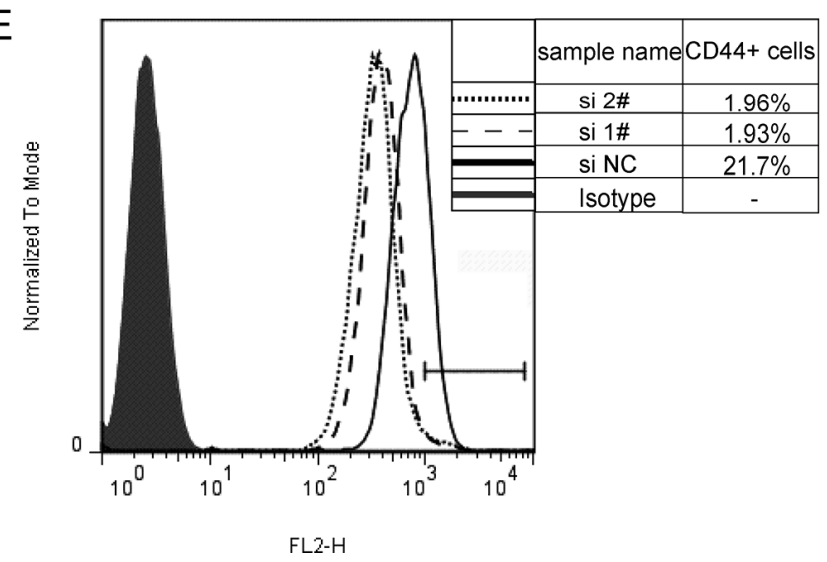

F

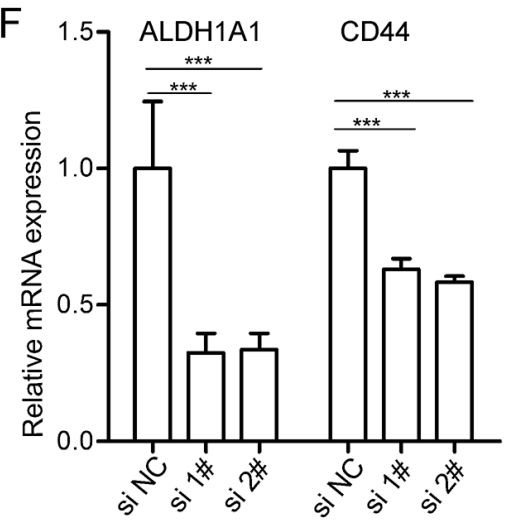

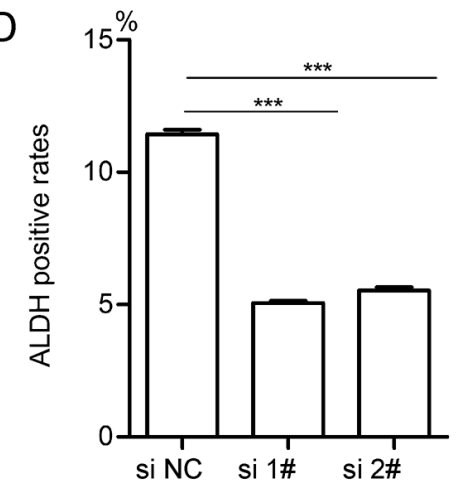

G

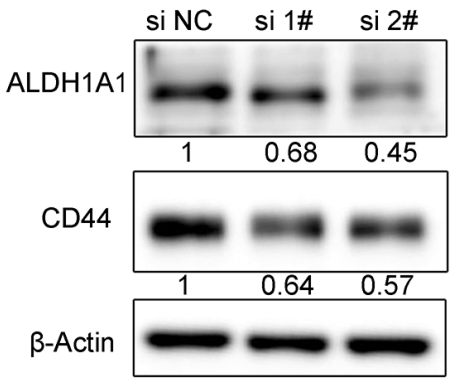

Figure 2. ASAP1-IT1 knockdown reduced UBC cell stemness. A. Knockdown efficiency of ASAP1-IT1 siRNAs (si 1\# and si 2\#) in T24, tested by qRT-PCR. $B$ and C Sphere formation assay was performed on the second day when T24 was transfected with ASAP1-IT1 siRNAs. Sphere number was counted 6 days later (B) and photos were taken at the meantime (C). D and E The changes of ALDH ${ }^{\text {high }}$ (D) and CD44 ${ }^{+}$(E) population of T24 when ASAP1-IT1 was knocked down, tested by flow cytometry. F and G The expression levels of CSC markers (ALDH1A1 and CD44) at mRNA level (F) and protein level (G) after ASAP1-IT1 knockdown. ImageJ software was used to semi-quantified bands. The digits shown below Western blots were the relative expression levels of indicated protein, compared to si NC groups, after normalized by $\beta$-Actin loading control. ${ }^{\star \star} p<0.01,{ }^{\star * \star} p<0.001$. 
A

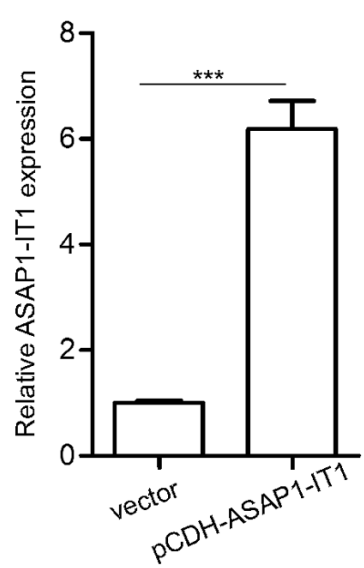

B

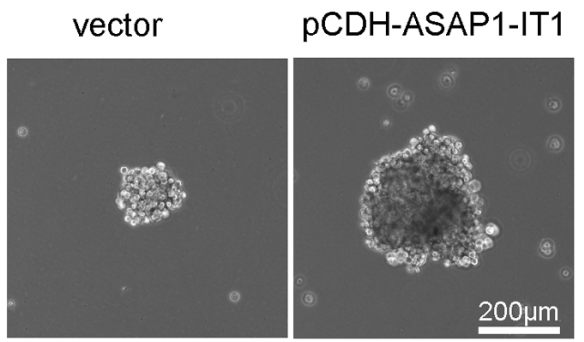

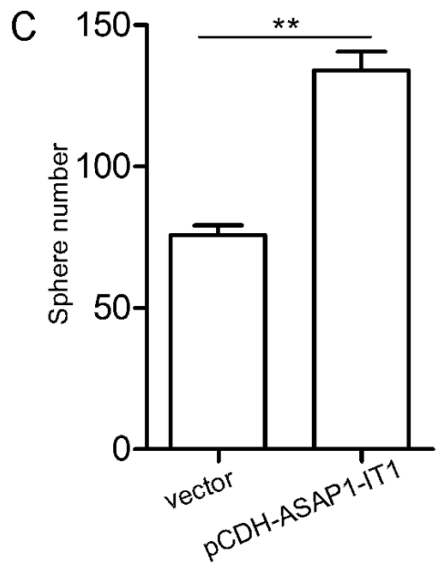

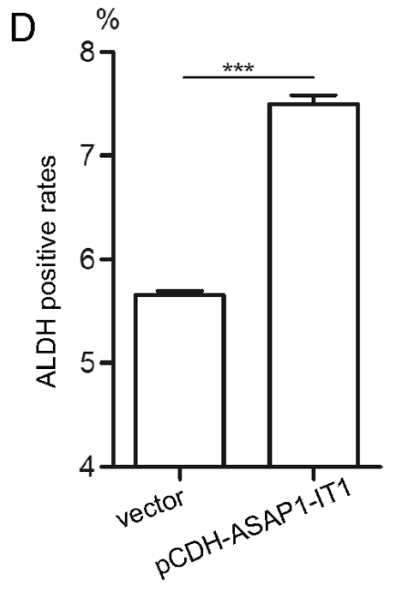

E

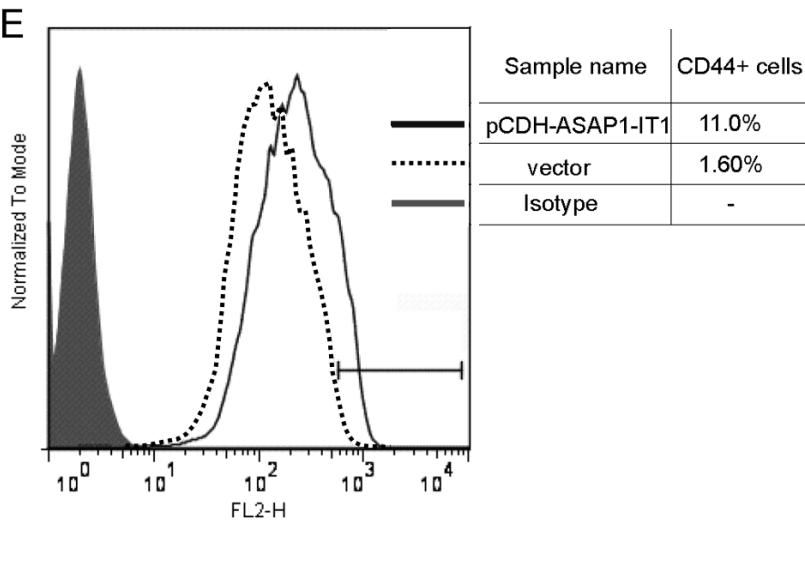

$\mathrm{F}$

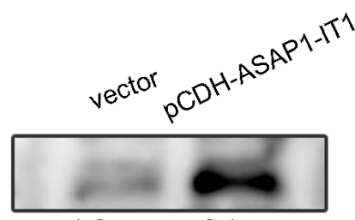

ALDH1A1

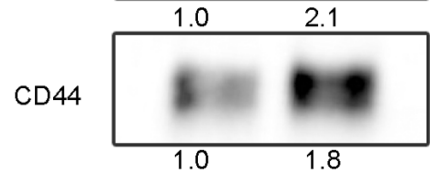

2.1

$\beta$-Actin

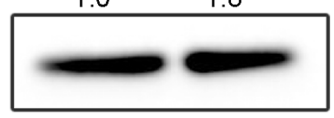

Figure 3. Overexpression of ASAP1-IT1 promoted UBC cell stemness. A. Overexpression efficiency of ASAP1-IT1 in J82 cells transfected with pCDHASAP1-IT1 was tested 48 hours later. B and C Sphere formation assay was performed on the second day when J82 was transfected with pCDH-ASAP1IT1. Sphere number was counted (B) and photos (C) were taken 5 days later. D and E The changes of ALDH ${ }^{\text {high }}(\mathrm{D})$ and CD44 $(E)$ population of J82 when ASAP1-IT1 was overexpressed, tested by flow cytometry. F. CSC markers (ALDH1 A1, CD44) expression change at protein level. ImageJ software was used to semi-quantified bands. The digits shown below Western blots are the relative expression levels of indicated proteins, compared to vector groups, after normalized by $\beta$-Actin loading control. ${ }^{* *} \mathrm{p}<0.01$, ${ }^{* * *} \mathrm{p}<0.001$.

tant metastases $(\mathrm{n}=18)$ [19]. Moreover, genome-wide SNP association studies have also revealed that sequence variant on $8 \mathrm{q} 24$ is associated with UBC risk [27]. In this region, oncogene c-Myc is one of the most investigated genes, which is strongly associated with high tumor grade and advanced tumor stage in UBC patients [28]. However, few studies focused on the biological role of lncRNAs at 8q24 in UBC progression.

A multitude of lncRNAs have been found to be expressed aberrantly and involved in the development of various human cancers, including UBC [29]. Recent studies identified cancer associated lncRNAs involved in many aspects of cancer hallmarks [12]. For instance, in UBC samples, lncRNAs, such as PANDA, H19, NEAT1, SUMO1P3, HOTAIR and SPRY4IT1, are overexpressed in tumor tissues and correlated with advanced tumor stage and poor prognosis. These lncRNAs are demonstrated to promote UBC cell proliferation or metastasis [30-35]. Our lab has also demonstrated that cancer-associated fibroblasts secret TGF- $\beta 1$ to induce EMT in UBC cells through directly inducing lncRNA-ZEB2NAT [36]. On the contrary, some lncRNAs, such as BANCR, GAS5 and DBCCR1-003 are downregulated in UBC specimens, working as proliferation or metastasis inhibitors [37-39]. Although a few $\operatorname{lncRNAs}$ (H19, MALAT-1, DANCER, HOXA11-AS and FOXF1-AS1) have been reported to be correlated with cancer stemness [16-18, 40,41 ], to our knowledge, no lncRNAs have been identified to regulate UBC cell stemness to date.

Herein, we confirmed that lncRNA ASAP1-IT1 is necessary and sufficient to enhance UBC cell stemness, with the altered expression levels of CSC markers, CD44 and ALDH1A1. CSCs are believed to contribute to UBC recurrence, metastasis and chemotherapy failure [42]. Several CSC markers are used in UBC, for example, cell surface markers (CD44 and 67LR) and cytokeratins (CK5, CK14 and CK17) [9]. CD44, a cell surface glycoprotein, is used as CSC marker in many kinds of cancers, such as breast cancer, prostate cancer, colon cancer, 
liver cancer [43]. Recent studies found that the tumorigenic potential of CD44 $4^{+} \mathrm{UBC}$ cells was 10-200 times greater than that of CD44- cancer cells. In addition, $\mathrm{CD} 44^{+} \mathrm{UBC}$ cells fulfilled all of the functional criteria of CSCs [10]. Aldehyde dehydrogenase $1 \mathrm{~A} 1$ (ALDH1A1) is another promising marker for bladder CSCs. Greater clonogenicity and tumorigenicity for ALDH1A1 ${ }^{+} \mathrm{UBC}$ cells compared to ALDH1A1 ${ }^{-}$cells was demonstrated by using an in vitro sphere formation assay and in vivo xenograft assays [11]. Besides, patients with high expression level of ALDH1A1 were four times more likely to experience tumor progression and decreased cancer-specific and overall survival than patients with low expression level of ALDH1A1 [11].

During preparation of this manuscript, Fu and colleagues reported that ASAP1-IT1 was highly expressed in low grade tumors and early stage of ovarian cancer, compared to high grade tumors and late stage disease. Its overexpression was associated with favorable overall survival of ovarian cancer patients [44]. The mechanism of how ASAP1-IT1 regulates ovarian cancer cells remains unresolved. Herein, we found that high expression of ASAP1-IT1 in UBC was positively associated with advanced tumor stage and predicted poor overall survival. Such clinical relevance was also supported by the notion that ASAP1-IT1 expression is sufficient and essential for maintenance of UBC stemness (Figure 2, Figure 3 and Supplementary Figure 1). Though it is not consistent with the association of ASAP1-IT1 with the clinicopathological parameters of ovarian cancers, the different expression changes of lncRNAs in different cancer types are not rare. For example, MALAT1, a long coding RNA which is overexpressed in liver, lung, colon, cervical cancer, is underexpressed in glioma samples [45]. Therefore, the roles of specific lncRNA in cancer cells may be dependent on cellular context.

As lncRNAs are large in size and have complicated and diversified structures, they have several regulatory capacities. First, lncRNAs take part in transcriptional and epigenetic regulations. They act as decoys, activators, guides, or scaffolds for their interacting proteins, such as histone modifier and transcription factors. Second, lncRNAs are important players in posttranscriptional regulation, such as reservoirs of microRNAs, mRNA editor, and mRNA splicing regulators [46, 47]. Further study on the mechanism underlying the regulation of CSC maintenance by ASAP1-IT1 is warranted.

In conclusion, we are the first to demonstrate that ASAP1-IT1 was overexpressed in human UBC specimens. Overexpression of ASAP1-IT1 was correlated with advanced tumor stage, higher clinical stage, poor pathological differentiation and predicted poor clinical outcome. ASAP1-IT1 is sufficient and necessary for maintenance of UBC stemness. Large-scale and long-term follow-up studies are encouraged to confirm the significance of this potential biomarker in UBC.

Acknowledgments: This study was funded by grants from the National Natural Science Foundation of China (81372168, 81470116,81672873 and 81572519), Wu Jieping Medical Foundation
(320.6750.16051), the Fundamental Research Funds for the Central Universities (090314380004) and the Natural Science Foundation for Universities in Jiangsu Province (BK20151396).

\section{References}

[1] SIEGEL RL, MILLER KD, JEMAL A. Cancer statistics, 2016. CA Cancer J Clin 2016; 66: 7-30. https://doi.org/10.3322/ caac. 21332

[2] KNOWLES MA, HURST CD. Molecular biology of bladder cancer: new insights into pathogenesis and clinical diversity. Nat Rev Cancer 2015; 15: 25-41. https://doi.org/10.1038/ $\underline{\operatorname{nrc} 3817}$

[3] WU XR. Urothelial tumorigenesis: a tale of divergent pathways. Nat Rev Cancer 2005; 5: 713-725. https://doi. org/10.1038/nrc1697

[4] KAUFMAN DS, SHIPLEY WU, FELDMAN AS. Bladder cancer. Lancet 2009; 374: 239-249. https://doi.org/10.1016/ S0140-6736(09)60491-8

[5] PRASAD SM, DECASTRO GJ, STEINBERG GD, MEDSCAPE. Urothelial carcinoma of the bladder: definition, treatment and future efforts. Nat Rev Urol 2011; 8: 631-642. https://doi.org/10.1038/nrurol.2011.144

[6] ALLEGRA A, ALONCI A, PENNA G, INNAO V, GERACE $\mathrm{D}$ et al. The cancer stem cell hypothesis: a guide to potential molecular targets. Cancer Invest 2014; 32: 470-495. https:// doi.org/10.3109/07357907.2014.958231

[7] PLAKS V, KONG N, WERB Z. The cancer stem cell niche: how essential is the niche in regulating stemness of tumor cells? Cell Stem Cell 2015; 16: 225-238. https://doi.org/10.1016/j. stem.2015.02.015

[8] GARG M. Urothelial cancer stem cells and epithelial plasticity: current concepts and therapeutic implications in bladder cancer. Cancer Metastasis Rev 2015; 34: 691-701. https://doi. org/10.1007/s10555-015-9589-6

[9] HO PL, KURTOVA A, CHAN KS. Normal and neoplastic urothelial stem cells: getting to the root of the problem. Nat Rev Urol 2012; 9: 583-594. https://doi.org/10.1038/nrurol.2012.142

[10] CHAN KS, ESPINOSA I, CHAO M, WONG D, AILLES L et al. Identification, molecular characterization, clinical prognosis, and therapeutic targeting of human bladder tumor-initiating cells. Proc Natl Acad Sci U S A 2009; 106: 14016-14021. https:// doi.org/10.1073/pnas.0906549106

[11] SU Y, QIU Q, ZHANG X, JIANG Z, LENG Q et al. Aldehyde dehydrogenase $1 \mathrm{~A} 1$-positive cell population is enriched in tumor-initiating cells and associated with progression of bladder cancer. Cancer Epidemiol Biomarkers Prev 2010; 19: 327-337. https://doi.org/10.1158/1055-9965.EPI-09-0865

[12] GUTSCHNER T, DIEDERICHS S. The hallmarks of cancer: a long non-coding RNA point of view. RNA Biol 2012; 9: 703-719. https://doi.org/10.4161/rna.20481

[13] HUARTE M. The emerging role of lncRNAs in cancer. Nat Med 2015; 21: 1253-1261. https://doi.org/10.1038/nm.3981

[14] GHOSAL S, DAS S, CHAKRABARTI J. Long noncoding RNAs: new players in the molecular mechanism for maintenance and differentiation of pluripotent stem cells. Stem 
Cells Dev 2013; 22: 2240-2253. https://doi.org/10.1089/ $\underline{\text { scd.2013.0014 }}$

[15] TORDONATO C, DI FIORE PP, NICASSIO F. The role of non-coding RNAs in the regulation of stem cells and progenitors in the normal mammary gland and in breast tumors. Front Genet 2015; 6: 72. https://doi.org/10.3389/ fgene.2015.00072

[16] JIAO F, HU H, HAN T, YUAN C, WANG L et al. Long noncoding RNA MALAT-1 enhances stem cell-like phenotypes in pancreatic cancer cells. Int J Mol Sci 2015; 16: 6677-6693. https://doi.org/10.3390/ijms16046677

[17] KIM HJ, EOH KJ, KIM LK, NAM EJ, YOON SO et al. The long noncoding RNA HOXA11 antisense induces tumor progression and stemness maintenance in cervical cancer. Oncotarget 2016. https://doi.org/10.18632/oncotarget.12863

[18] YUAN SX, WANG J, YANG F, TAO QF, ZHANG J et al. Long noncoding RNA DANCR increases stemness features of hepatocellular carcinoma by derepression of CTNNB1. Hepatology 2016; 63: 499-511. https://doi.org/10.1002/hep.27893

[19] VISAPAA H, SELIGSON D, EEVA M, GABER F, RAO J et al. 8q24 amplification in transitional cell carcinoma of bladder. Appl Immunohistochem Mol Morphol 2003; 11: 33-36. https://doi.org/10.1097/00129039-200303000-00006

[20] HOU T, YANG C, TONG C, ZHANG H, XIAO J et al. Overexpression of ASAP1 is associated with poor prognosis in epithelial ovarian cancer. Int J Clin Exp Pathol 2014; 7: 280-287.

[21] MULLER T, STEIN U, POLETTI A, GARZIA L, ROTHLEY $\mathrm{M}$ et al. ASAP1 promotes tumor cell motility and invasiveness, stimulates metastasis formation in vivo, and correlates with poor survival in colorectal cancer patients. Oncogene 2010; 29: 2393-2403. https://doi.org/10.1038/onc.2010.6

[22] LI L, JIA F, BAI P, LIANG Y, SUN R et al. Association between polymorphisms in long non-coding RNA PRNCR1 in 8q24 and risk of gastric cancer. Tumour Biol 2016; 37: 299-303. https://doi.org/10.1007/s13277-015-3750-2

[23] TSENG YY, MORIARITY BS, GONG W, AKIYAMA R, TIWARI A et al. PVT1 dependence in cancer with MYC copy-number increase. Nature 2014; 512: 82-86. https://doi. org/10.1038/nature13311

[24] RAEDER MB, BIRKELAND E, TROVIK J, KRAKSTAD C, SHEHATA $S$ et al. Integrated genomic analysis of the 8q24 amplification in endometrial cancers identifies ATAD2 as essential to MYC-dependent cancers. PLoS One 2013; 8: e54873. https://doi.org/10.1371/journal.pone.0054873

[25] TOMINAGA E, TSUDA H, ARAO T, NISHIMURA S, CHIYODA $\mathrm{T}$ et al. Use of amplification of the 8q24 and 20q11-13 loci to predict progression-free survival of advanced epithelial ovarian cancer patients receiving standard therapy. J Clin Oncol 2009; 27: e16526.

[26] ZAHARIEVA B, SIMON R, RUIZ C, OEGGERLI M, MIHATSCH MJ et al. High-throughput tissue microarray analysis of CMYC amplificationin urinary bladder cancer. Int J Cancer 2005; 117: 952-956. https://doi.org/10.1002/ijc.21253

[27] ROTHMAN N, GARCIA-CLOSAS M, CHATTERJEE N, MALATS N, WU X et al. A multi-stage genome-wide association study of bladder cancer identifies multiple susceptibility loci. Nat Genet 2010; 42: 978-984. https://doi.org/10.1038/ ng.687

[28] SAUTER G, CARROLL P, MOCH H, KALLIONIEMI A, KERSCHMANN R et al. c-myc copy number gains in bladder cancer detected by fluorescence in situ hybridization. Am J Pathol 1995; 146: 1131-1139.

[29] CHEETHAM SW, GRUHL F, MATTICK JS, DINGER ME. Long noncoding RNAs and the genetics of cancer. Br J Cancer 2013; 108: 2419-2425. https://doi.org/10.1038/bjc.2013.233

[30] BERRONDO C, FLAX J, KUCHEROV V, SIEBERT A, OSINSKI T et al. Expression of the Long Non-Coding RNA HOTAIR Correlates with Disease Progression in Bladder Cancer and Is Contained in Bladder Cancer Patient Urinary Exosomes. PLoS One 2016; 11: e0147236. https://doi.org/10.1371/journal. pone. 0147236

[31] LUO M, LI Z, WANG W, ZENG Y, LIU Z et al. Long noncoding RNA H19 increases bladder cancer metastasis by associating with EZH2 and inhibiting E-cadherin expression. Cancer Lett 2013; 333: 213-221. https://doi.org/10.1016/j. canlet.2013.01.033

[32] XIANGUO C, ZONGYAO H, JUN Z, SONG F, GUANGYUE $\mathrm{L}$ et al. Promoting progression and clinicopathological significance of NEAT1 over-expression in bladder cancer. Oncotarget 2016. https://doi.org/10.18632/oncotarget.10084

[33] ZHAN Y, LIN J, LIU Y, CHEN M, CHEN X et al. Up-regulation of long non-coding RNA PANDAR is associated with poor prognosis and promotes tumorigenesis in bladder cancer. J Exp Clin Cancer Res 2016; 35: 83. https://doi.org/10.1186/ s13046-016-0354-7

[34] ZHAN Y, LIU Y, WANG C, LIN J, CHEN M et al. Increased expression of SUMO1P3 predicts poor prognosis and promotes tumor growth and metastasis in bladder cancer. Oncotarget 2016; 7: 16038-16048. https://doi.org/10.18632/ oncotarget.6946

[35] ZHAO X, ZHAO Z, XU W, HOU J, DU X. Increased expression of SPRY4-IT1 predicts poor prognosis and promotes tumor growth and metastasis in bladder cancer. Int J Clin Exp Pathol 2015; 8: 1954-1960.

[36] ZHUANG J, LU Q, SHEN B, HUANG X, SHEN L et al. TGFbetal secreted by cancer-associated fibroblasts induces epithelial-mesenchymal transition of bladder cancer cells through lncRNA-ZEB2NAT. Sci Rep 2015; 5: 11924. https:// doi.org/10.1038/srep11924

[37] HE A, LIU Y, CHEN Z, LI J, CHEN M et al. Over-expression of long noncoding RNA BANCR inhibits malignant phenotypes of human bladder cancer. J Exp Clin Cancer Res 2016; 35: 125. https://doi.org/10.1186/s13046-016-0397-9

[38] LIU Z, WANG W, JIANG J, BAO E, XU D et al. Downregulation of GAS5 promotes bladder cancer cell proliferation, partly by regulating CDK6. PLoS One 2013; 8: e73991. https:// doi.org/10.1371/journal.pone.0073991

[39] QI D, LI J, QUE B, SU J, LI M et al. Long non-coding RNA DBCCR1-003 regulate the expression of DBCCR1 via DNMT1 in bladder cancer. Cancer Cell Int 2016; 16: 81. https://doi. org/10.1186/s12935-016-0356-8

[40] BAUDERLIQUE-LE ROY H, VENNIN C, BROCQUEVILLE G, SPRUYT N, ADRIAENSSENS E et al. Enrichment of 
Human Stem-Like Prostate Cells with s-SHIP Promoter Activity Uncovers a Role in Stemness for the Long Noncoding RNA H19. Stem Cells Dev 2015; 24: 1252-1262. https://doi. org/10.1089/scd.2014.0386

[41] MIAO L, HUANG Z, ZENGLI Z, LI H, CHEN Q et al. Loss of long noncoding RNA FOXF1-AS1 regulates epithelial-mesenchymal transition, stemness and metastasis of non-small cell lung cancer cells. Oncotarget 2016; 7: 68339-68349. https:// doi.org/10.18632/oncotarget.11630

[42] OHISHI T, KOGA F, MIGITA T. Bladder Cancer Stem-Like Cells: Their Origin and Therapeutic Perspectives. Int J Mol Sci 2015; 17: 43. https://doi.org/10.3390/ijms17010043

[43] MOGHBELI M, MOGHBELI F, FORGHANIFARD MM, ABBASZADEGAN MR. Cancer stem cell detection and isolation. Med Oncol 2014; 31: 69. https://doi.org/10.1007/ s12032-014-0069-6
[44] FU Y, BIGLIA N, WANG Z, SHEN Y, RISCH HA et al. Long non-coding RNAs, ASAP1-IT1, FAM215A, and LINC00472, in epithelial ovarian cancer. Gynecol Oncol 2016; 143: 642-649. https://doi.org/10.1016/j.ygyno.2016.09.021

[45] HAN Y, ZHOU L, WU T, HUANG Y, CHENG Z et al. Downregulation of lncRNA-MALAT1 Affects Proliferation and the Expression of Stemness Markers in Glioma Stem Cell Line SHG139S. Cell Mol Neurobiol 2016; 36: 1097-1107. https:// doi.org/10.1007/s10571-015-0303-6

[46] YANG G, LU X, YUAN L. LncRNA: a link between RNA and cancer. Biochim Biophys Acta 2014; 1839: 1097-1109. https:// doi.org/10.1016/j.bbagrm.2014.08.012

[47] CHEN J, MIAO Z, XUE B, SHAN Y, WENG G et al. Long Non-coding RNAs in Urologic Malignancies: Functional Roles and Clinical Translation. J Cancer 2016; 7: 1842-1855. https://doi.org/10.7150/jca.15876 

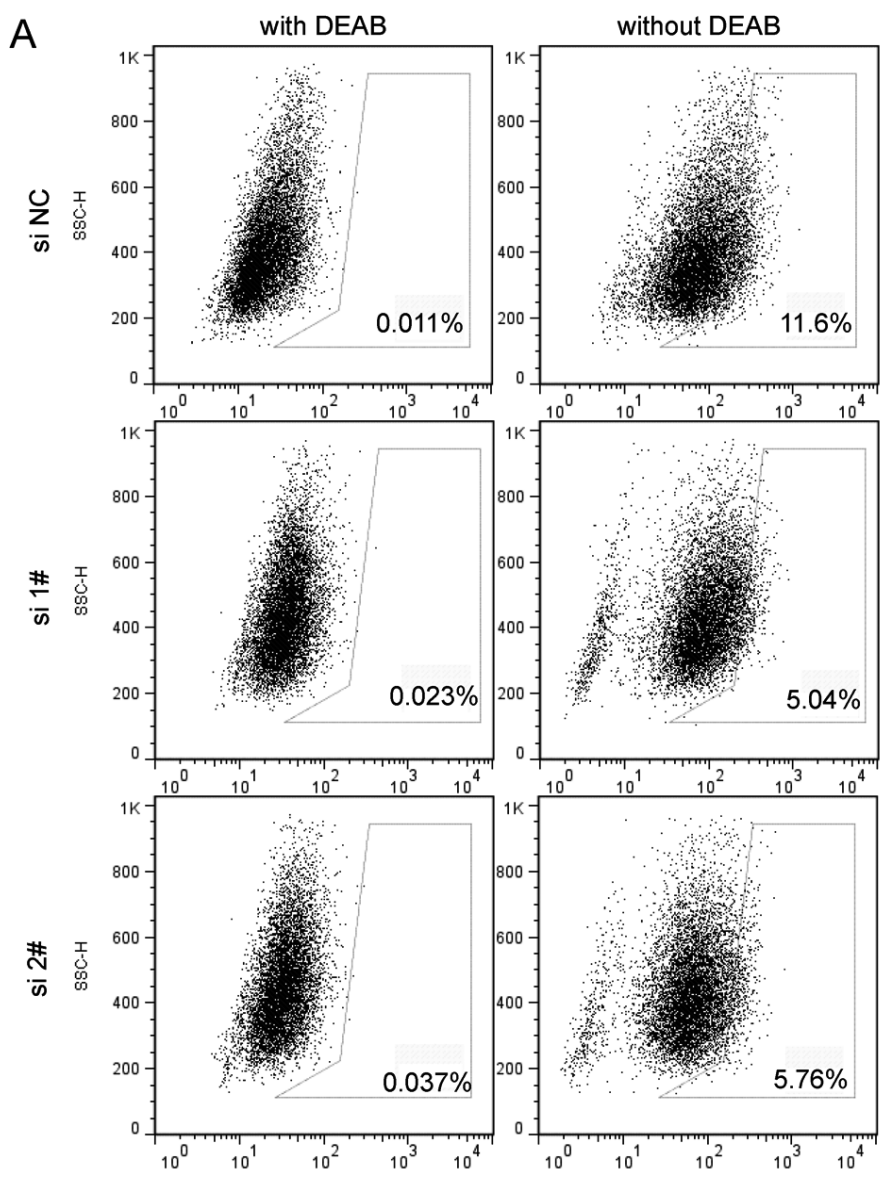

B
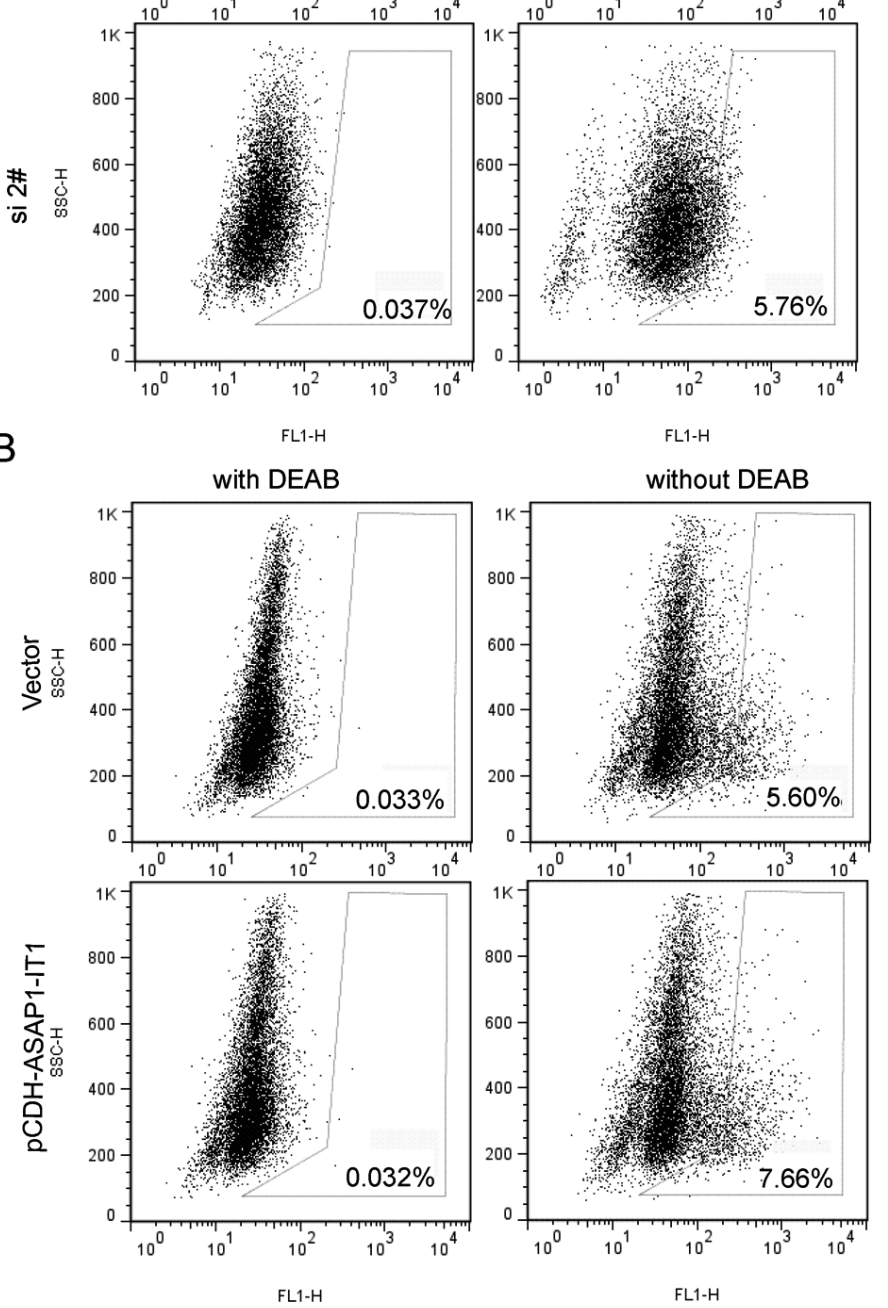

Supplementary Figure 1. ALDEFLUOR assay of T24 and J82 with ASAP1-IT1 knockdown or overexpression. A. The change of ALDH ${ }^{\text {high }}$ population of T24 when ASAP1-IT1 was knocked down, tested by flow cytometry. B. The change of ALDH ${ }^{\text {high }}$ population of J82 when ASAP1-IT1 was overexpressed, tested by flow cytometry 